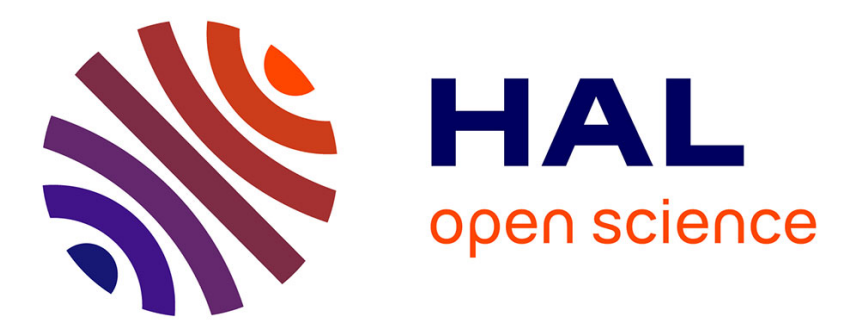

\title{
Design of a High-Speed Permanent Magnet Motor for the Drive of a Fuel Cell Air-Compressor
}

\author{
Frédéric Dubas, Christophe Espanet, A. Miraoui
}

\section{To cite this version:}

Frédéric Dubas, Christophe Espanet, A. Miraoui. Design of a High-Speed Permanent Magnet Motor for the Drive of a Fuel Cell Air-Compressor. IEEE Véhicular Power and Propulsion (VPP), Sep 2005, Chicago, United States. pp.603-610. hal-00322444

\section{HAL Id: hal-00322444 \\ https://hal.science/hal-00322444}

Submitted on 17 Sep 2008

HAL is a multi-disciplinary open access archive for the deposit and dissemination of scientific research documents, whether they are published or not. The documents may come from teaching and research institutions in France or abroad, or from public or private research centers.
L'archive ouverte pluridisciplinaire HAL, est destinée au dépôt et à la diffusion de documents scientifiques de niveau recherche, publiés ou non, émanant des établissements d'enseignement et de recherche français ou étrangers, des laboratoires publics ou privés. 


\title{
Design of a High-Speed Permanent Magnet Motor for the Drive of a Fuel Cell Air-Compressor
}

\author{
(Invited paper)
}

\author{
F. Dubas, C. Espanet, Member, IEEE, and A. Miraoui \\ Electrical Engineering and Systems Laboratory (L2ES), joint Research Unit of the University of Technology of Belfort- \\ Montbéliard (UTBM) and the University of Franche-Comté (UFC) - EA 3898 \\ L2ES/UTBM (Bat. F), Rue Thierry MIEG, F90010 Belfort. \\ E-mail: frederic.dubas@utbm.fr, christophe.espanet@univ-fcomte.fr, and abdellatif.miraoui@utbm.fr \\ Tel: +33 (0)3 84583600 - Fax: +33 (0)3 84583636
}

\begin{abstract}
This paper deals with the design of a $500 \mathrm{~W}$ permanent magnet (PM) machine used to drive the aircompressor of a $5 \mathrm{~kW}$ fuel cell (FC). The authors focus on the optimization of the motor efficiency in order to minimize the energy consumption of the air-compressor which can represent up to $30 \%$ of the electrical energy delivered by the FC. The authors justify the use of a PM machine by the fact that, by using rare earth Nd-Fe-B magnets, such a type of machine makes it possible to reach a high efficiency as well as a high power density. The optimized machine presented in this paper have theoretically more than $25 \%$ of its working area with an efficiency higher than $90 \%$ and the efficiency at the rated point equals to $92 \%$. Those promising results of computation are confirmed by the first experimental results obtained with a prototype.
\end{abstract}

Index Terms-Fuel cell, auxiliary components, compressor, high-speed permanent magnet machine, efficiency

\section{INTRODUCTION}

Fuel Cell Systems (FCS) offer clean and efficient energy production. Since last 10 years, intensive researches and developments have been done in order to achieve industrial systems for both stationary and mobile applications. Different issues must be solved, but, considering the mobile applications, and more particularly the ones of transport, the efficiency of the system is the key issue. To improve this feature, the whole system, and not only the stack, must be considered. Different ancillaries are necessary to produce the electrical energy. Basically, considering a Polymer Electrolyte Membrane Fuel Cell (PEMFC), commonly considered as a good candidate for automotive applications [1, 2, 3], the FCS consists of 6 subsystems [see Figure 1]:

- the hydrogen supply, which often consists of an hydrogen tank associated with a pressure reducer;

- the air (oxygen) supply, which often consists of compressor, possibly coupled to a turbine;

- the humidifier to maintain gas and membrane hydration;

- the cooling circuit, to extract the heat produced during the electrochemical reaction;

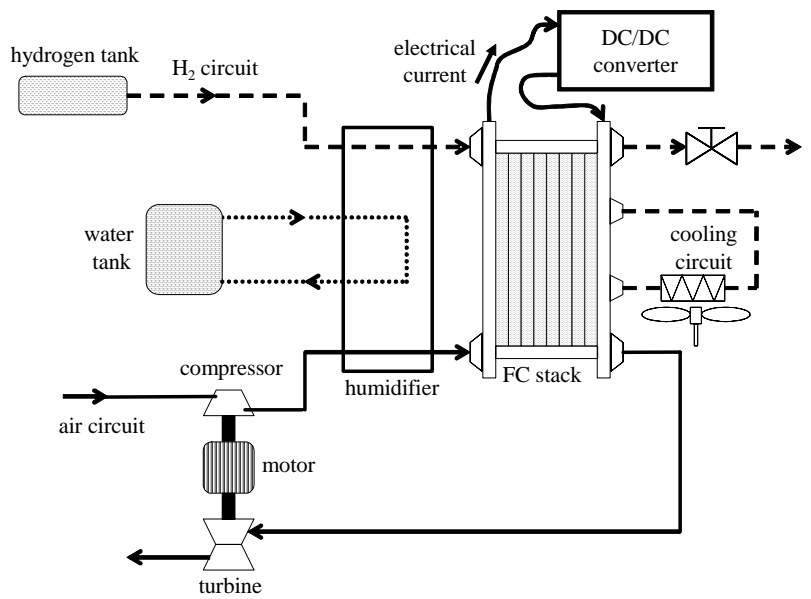

Figure 1. Basic schema of a fuel cell system

- the static converter to realize the interface between the FC and the direct current (DC) bus;

- and finally the supervision system to control the different working variables (temperature, air flow, hydrogen flow, hydration of membranes...) and to supervise the safety of the system.

For mobile applications, the previous ancillaries are fed by the FC itself. Then, the energy consumption of the pumps, compressors... must be provided by the stack and it can represent up to $40 \%$ of the produced energy. Consequently, it highly decreases the efficiency of the FCS. Among the whole ancillaries, the air-compressor is a key one, because it is the most power-hungry (approximately $80 \%$ of the system's intrinsic power consumption). Then, the optimization of the FCS efficiency needs to take care of the compressor, its driving motor and its control. In this paper, the authors focus on the optimal design of the electrical machine.

Even if the aim of this paper is not to design the compressor, its choice has an influence on the specifications and the design of the electrical machine. Different types of compressor are available and the following specifications must be verified, whatever the power of the FCS:

- the compressor should not be lubricated with oil because the FC stack can not support even ppm of oil; 
then, only possible lubrication must be carried out with air or water;

- the air flow must be controlled directly by the speed rotation of the electrical motor, in order to have the best dynamic behaviour;

- $\quad$ the ripple of the absolute pressure at the output of the compressor must be lower than 0.1 bar;

- $\quad$ and finally the lifetime must be at least 8000 hours (equivalent to automotive constraints).

Another interesting option is to couple the compressor with a turbine in order to recover a part of the energy of the FC exhaust gases. In this case, the rotational speed must be higher than $10,000 \mathrm{rpm}$, in order to reach a sufficient efficiency of energy recovery.

By comparing the different technologies, the scroll-type compressor seems to be the best adapted to the previous constraints. Indeed, it has a good efficiency over the whole speed range, it permits to have a regular compression (with a low pressure ripple), the compression rate is sufficient (easily higher than 3) and the compression chambers can be isolated from the other parts of the compressor, so that the pollution of the air can be removed or, at least, minimized.

The final aim of this work is to realize the machine and to test it, firstly with a classical test bench and secondly associated with a compressor in a FCS. Then, the authors have chosen a realistic power of the FCS, which equals to $5 \mathrm{~kW}$. Indeed, a FCS of $5 \mathrm{~kW}$ is available at the Laboratory of Electrical Engineering and Systems (L2ES) [see Figure 2], so that the motor can be tested in real conditions. On the other hand, this power is compatible with the traction of a small vehicle, such as a scooter, or an Auxiliary Power Unit (APU) dedicated to automotive applications. Considering this level of power, the specifications of the machine are the following:

- maximal rotational speed: $10,000 \mathrm{rpm}$;

- mechanical power: $500 \mathrm{~W}$ (at 10,000 rpm);

- maximal electrical power: 1,000 W (lower than $20 \%$ of the FC power);

- efficiency at $500 \mathrm{~W}$ and 10,000 rpm: $>91 \% \mathrm{~min}$.

Moreover, the design must be realistic in order to be embedded on a vehicle and to have an objective cost series, if possible, compatible with the automobile application.

In the next sections, the authors present the design of a brushless motor and both theoretical electric and electromechanical characteristics. In the last section they also give the first experimental results obtained with a classical test bench.

\section{DESIGN OF THE MACHINE}

In this section, the aim is not to describe the whole calculations of the motor design (already published in other papers [4], [5] and [6]), but only to present the used methodology and to detail the outlines of each step, mainly by explaining the points directly linked with the particular considered application.

\section{A. Methodology of Design}

The methodology of design consists of five steps:

- $\quad$ the choice of the type of electrical machine among the classical available technologies;

- the design of the stator (choice of the lamination material and choice of the winding);

- $\quad$ the design of the rotor (choice of the PM and rotor yoke materials, limits of PM height...);

- a final optimization of the whole geometrical parameters, by using a large analytical model (AM), in order to find the structure having the best efficiency;

- a validation of the performances of the optimal machine by using a numerical model, with 2D finiteelement method (FEM) [7].

All those points are detailed in the following paragraphs.

\section{B. Choice of the Type of Machine}

A quick comparison of the five classical technologies has been achieved. It results that the PM synchronous machine (PMSM) seems to be a good candidate.

Indeed, the asynchronous machine (ASM), which presents the interest of a low price and a good reliability, has a lower specific power than synchronous machines (particularly excited with high energy PM) and, its efficiency is always lower than the one obtained with a PMSM, due to the fact that, even with an advanced control, its working requires losses in the rotor as well as in the stator. Finally, the power factor of the ASM will be lower, because reactive power is always necessary to magnetize the machine.

With the considered level of power $(500 \mathrm{~W})$, the DC machine (DCM) with brushes is used a lot in automotive applications, for example for electrical fans. Indeed, it has the advantage of a low cost and the control is easy to develop. But it presents at least two disadvantages. Firstly, in the desired range of rotational speed and power, the price of the collector will be high and its reliability low. Secondly, as for the ASM, the specific power and the efficiency of the DCM are lower than the ones obtained with PMSM, mainly because of the mechanical collector.

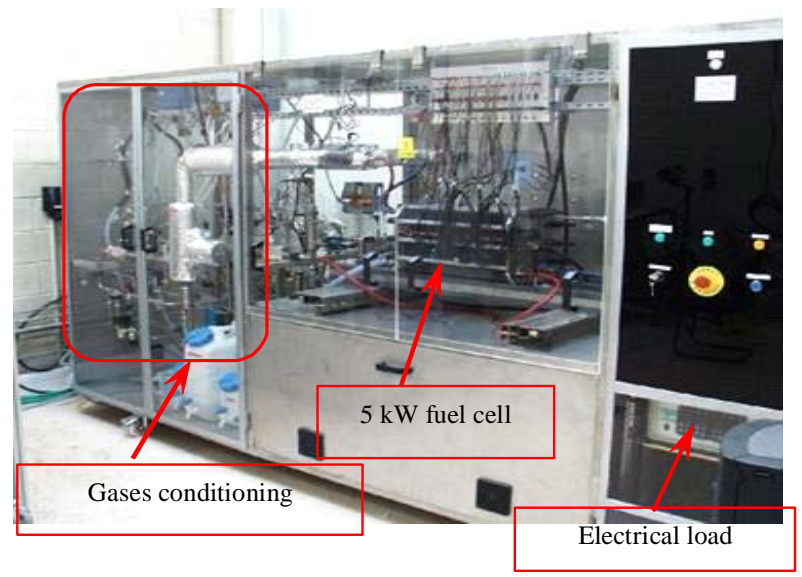

Figure 2. $5 \mathrm{~kW} \mathrm{FC}$ test bench in the L2ES 
The synchronous machine with wound rotor has large overall dimensions and a lower specific power than a PMSM (with high energy PM), even if the flux weakening is easier to achieve. Moreover, the rotor losses are a cooling issue.

The variable reluctance machine (VRM) could be another good candidate. The construction is easy and it has a lower cost than a machine with PM. The machine can easily reach high-speed. The only limitation could be the vibrations due to torque ripple possibly more important with a VRM than with a PMSM. Those vibrations could create problems of reliability of the FCS due to air pressure ripples.

Finally, the authors chose deliberately to design a PMSM, but other works concerning the design of RMV (particularly with passive rotor) are under development in the L2ES. Further deep comparisons of the performances, the cost and the industrialization of those two machines are necessary to do the final choice.

\section{Design of the Stator}

The design of the stator consists of choosing the lamination material, the type of winding and to calculate their geometrical parameters. This last calculation is achieved globally by optimizing the whole geometrical parameters of the machine (see paragraph II.E).

The choice of the lamination material depends on three main constraints which are the level of saturation, the level of the iron losses and the cost. A compromise between those previous constraints is to use classical Fe-Si laminations with a thickness $e_{t}$ of $0.35 \mathrm{~mm}$ and specific iron losses $p_{\text {fer }}$ of $270 \mathrm{~W}$ for a sinusoidal flux density $(50 \mathrm{~Hz}-1 \mathrm{~T})$. With such a material, the level of saturation equals to $1.7 \mathrm{~T}$. The iron losses and the level of saturation could be better by using special alloys such as Fe-Co for example, but the cost will be around ten times higher and the manufacturing more complicate.

The type of winding is mainly linked to the fed of the machine. Basically, two types of fed are possible. The first one consists of feeding the stator with rectangular currents. In this case, the back electromotive force (EMF) of each phase must have an ideal trapezoidal form to provide a constant torque and, consequently, the coil span $\tau_{c p}$ must be diametric in order to keep the harmonic of the magnetic flux density. By using such a fed, the behaviour of the machine is quite similar to the one of a DCM with a mechanical collector and the control is easy. But the magnetic flux density of stator will have a lot of harmonic, leading to excess iron losses at high frequency. Moreover, the flux weakening (useful to reach high-speed) will create additional torque ripples. The other solution is to feed the stator with sinusoidal currents. In this case, a constant torque is obtained when the back EMF have sinusoidal shapes, whatever the phase difference between the current and the back EMF. The authors have chosen such a configuration in order to minimize the iron losses and the torque ripples when the control needs to modify the phase difference between the current and the back EMF. Then, an overlapping three-phased winding with two layers, a winding pitch $y_{w p}$ of 5/6 (shortening step) and two slots per pole and per phase has been used.

\section{Design of the Rotor}

The design of the rotor consists of choosing the number of pole pairs and the PM and rotor yoke materials. Moreover, a preliminary magnetic analysis was developed and made it possible to choose the PM magnetization.

First, the authors have chosen the lowest number of pole pairs, i.e. one. This choice permits to limit the electrical frequency and, consequently, the iron losses. It is clear that the specific power of the machine decreases with the number of pole pairs due to the increase of the section of the magnetic circuit, but, the main constraint of the studied application is to minimize the energy consumption and, for a high-speed machine, the iron losses are often the key component of the losses.

To have the maximal interest of using a PMSM and to maximize both specific power and efficiency, the author chose to use rare earth Nd-Fe-B magnets. Their magnetic characteristics are given in the TABLE I. This type of PMs makes it possible to reach high flux density in the air-gap (typically around $0.8 \mathrm{~T}$ ), leading to a reduction of the stator MMF and the copper losses for a given torque. But, the magnetic flux sections must be adapted in order to limit the level of flux density and, consequently, the level of iron losses. The optimization of the efficiency will lead to a compromise between the iron losses and the copper losses, by finding the right thickness of the rotor and stator yokes and the right teeth width.

Concerning the PM type of magnetization, the authors have developed a preliminary magnetic analysis proving the interest of using parallel magnetization. To do that, the authors have used an AM which consists of computing the exact solutions of the Maxwell equations in the air-gap and the PM by assuming that the permeability of the iron is infinite and by using the Carter's coefficient $K_{c}$ [8] to define an equivalent non salient machine. The complete analysis has been detailed in references [4] [5] and only the outlines are presented here.

The Figure 3 gives the evolution of the no-load flux density in the air-gap versus the radial thickness of the PM, $h_{m}$, for a given machine ${ }^{1}$, for two polarities ( $p=1$ and $p=12$ ) and for

TABLE I

CHARACTERISTICS OF THE PM

\begin{tabular}{lr}
\hline \hline Characteristics & Values \\
\hline Remanent flux density at $20^{\circ} \mathrm{C}[\mathrm{T}]$ & 1.13 \\
Coercitive magnetic field strength $[\mathrm{kA} / \mathrm{m}]$ & -873.9 \\
Relative magnetic permeability at $20^{\circ} \mathrm{C}[-]$ & 1.029 \\
Coefficient of temperature of remanent flux density $[\% / \mathrm{K}]$ & -0.12 \\
Coefficient of temperature of magnetic field $[\% / \mathrm{K}]$ & -0.6 \\
Electrical resistivity $\left[10^{-6} \Omega \cdot \mathrm{m}\right]$ & 1.44 \\
\hline \hline
\end{tabular}

1 The stator is external and its internal radius equals to $10 \mathrm{~mm}$; the air-gap equals to $1 \mathrm{~mm}$ and the ratio of the PM pole-arc to the pole-pitch is 1 . 


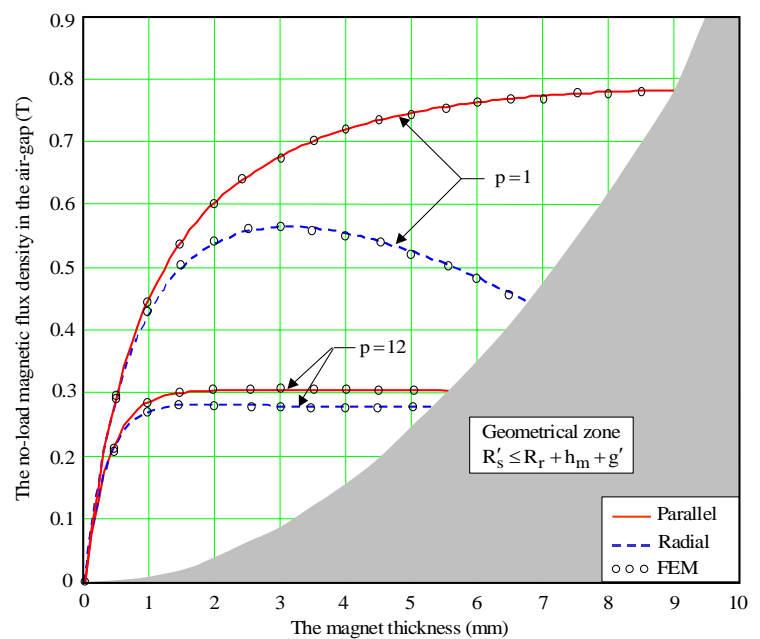

Figure 3. Evolution of the no-load air-gap magnetic flux density at the level of the external radius of the stator

both parallel and radial magnetization. This figure clearly shows the existence of a maximum for the case of a radial magnetization. It is an interesting result, because it defines a maximal value of the PM height: if the height is higher than this limit, the flux will decrease due to large leakages between two consecutive PM [5]. However, it also shows clearly that, for the same thickness (i.e. the same volume and the same cost), the parallel magnetization offers a better flux density than the radial one. That is one of the two reasons why they chose this type of magnetization. The other one is that, for a machine with two poles and a ratio of the PM pole-arc to the pole-pitch $\alpha_{p}$ of 1 , the radial component of the air-gap magnetic flux density has a sinusoidal shape. This permits to obtain more easily a sinusoidal back EMF as requested by the chosen type of fed.

The last constraint concerning the PM is the definition of a minimal value linked to the limit of demagnetization. Two cases must be considered. The first is classical and refers to the behaviour at maximal load (in normal or abnormal working). Indeed, the armature reaction field can be intensive for high values of stator current (occurring for example during a short circuit). In such a situation, the polarization may become lower than $90 \%$ of its saturation value, leading to a local or total demagnetization. The second case refers to the construction of the machine. During the PM bonding, the rotor

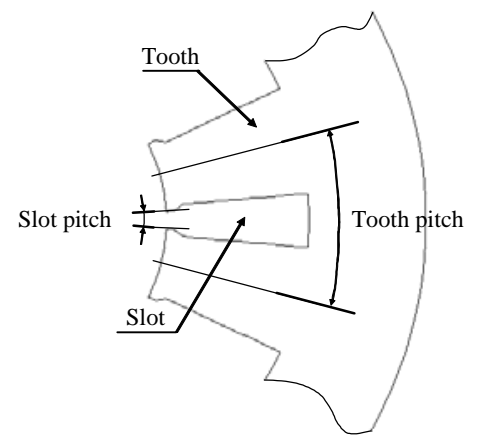

Figure 4. Geometry of the slot is not inserted in the stator; then the PM are submitted to the air demagnetizing field [9]. If the temperature is high (for example if the rotor is placed in a soaking tank), there is also a risk of demagnetization. Those two cases must be carefully studied to define the minimal value of the PM height permitting to protect it against the demagnetization. The final value of the PM height is given by optimization.

Another important issue is the mechanical aspects of the PM. Due to the high rotational speed, a retaining sleeve is necessary to maintain the PM [10]. The authors have chosen a non-conductive ring [see Figure 7(a)] to remove the losses due to the eddy-currents.

Finally, the last issue is the eddy-current losses in the turning parts (i.e. PM and rotor yoke). Due to the high conductivity of the Nd-Fe-B PM (in comparison with the ferrite ones), eddy-currents can be induced in the PM and the rotor yoke. Those currents have two origins. The first one is the fluctuation of the magnetic flux density in the PM due to the slot effect (during both load and no-load workings). Those later are nearly removed by using a tooth shoe leading to a very small slot-opening [see Figure 4]. Then, the second origin deals with the time and spatial harmonics of the stator magnetomotive force (MMF). To compute the eddy-currents in the turning parts, the authors have developed a second AM. As for the study of the air-gap magnetic flux density, this model consists of solving the diffusion equation in the PM and the rotor yoke. The exact solutions are expressed as a complex Fourier series and involve modified Bessel functions of the first and second kinds to model the radial repartition of the eddy-currents. The losses are computed by using the Poynting's vector. The whole modelling is detailed in reference [6] and the authors only give in Figure 5 the evolution of the eddy-current losses in the turning parts versus the rotational speed with a slotted stator and a slotless stator for the designed machine (whose parameters are given further in the TABLE II). The curves obtained by both analytical and 2D FEM calculations show the accuracy of the analytical computation. One can thus note that the losses resulting from stator slotting permeance harmonics are quite negligible because of the low ratio of the slot pitch over the tooth pitch. Moreover the value of the losses is low, so that it is not necessary to use laminations at the rotor yoke; magnetic solid steel, such as alloy Id $35 \mathrm{~cd} 4$, can be used. For the same reason, none segmentation of the PM is useful.

TABLE II

MAIN PARAMETERS OF A BRUSHLESS MOTOR WITH INTERNAL ROTOR

\begin{tabular}{lr}
\hline \hline Parameters & Values \\
\hline Axial length of PM [mm] & 45 \\
Carter's coefficient [-] & 1.011 \\
The slot pitch to the tooth pitch ratio [\%] & 20 \\
The outer PM radius to the inner stator radius modified by & 94.7 \\
Carter's coefficient [\%] & 73.7 \\
The outer rotor yoke radius to the outer PM radius ratio [\%] & 0 \\
The inner rotor yoke radius to the outer rotor yoke radius ratio [\%] & 1123 \\
Relative magnetic permeability of rotor yoke [-] & 2.366 \\
Electrical resistivity of rotor yoke [10 $\Omega \cdot \mathrm{m}]$ & 48 \\
Number of series turns per phase [-]
\end{tabular}




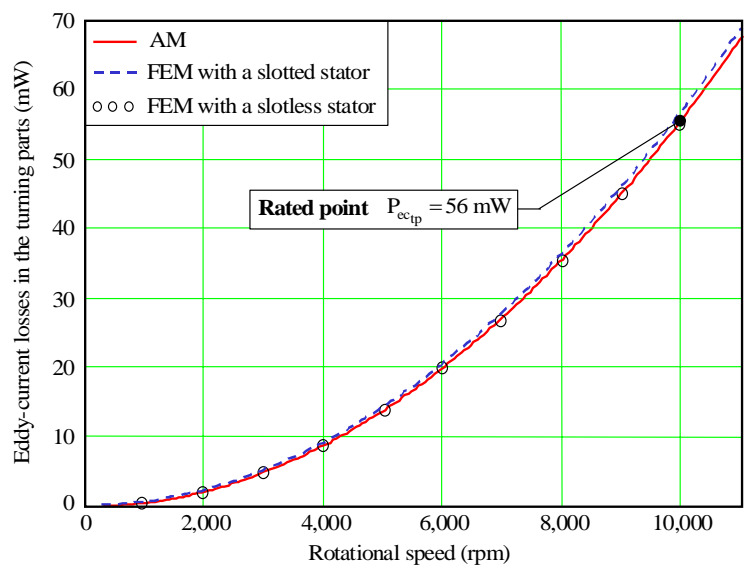

Figure 5. Evolution of the eddy-current losses in the turning parts versus the rotational speed

\section{E. Optimization of the Machine}

As explained in the previous paragraph, the whole geometrical parameters have been optimized to maximize the efficiency of the machine. To achieve the optimization, the authors have developed a complete AM of the electromagnetic behaviour of the machine. This model has two parts.

The first part of the model deals with the expressions of the whole magnetic variables obtained by using the model described in the previous section. Knowing the magnetic potential vector in the air-gap, the PM and the rotor yoke, it is possible to express the magnetic flux density in the whole machine, the back EMF and the electromagnetic torque, taking into account the influence of rotor and PM iron losses.

The second part of the model deals with a classical singlephased equivalent circuit of the machine which is, in fact, a representation of the power balance in the machine [see Figure 6]. In this single-phased equivalent circuit, $V_{p h}$ is the RMS value of the voltage applied to one phase, $R_{p h}$ and $X_{p h}$ are respectively the resistance and the reactance of one phase, $E_{p h}$ is the RMS value of the back EMF and $R_{\text {iron }}$ a virtual resistance used to model the influence of the stator iron losses. In fact, this circuit permits to express the losses and the efficiency, as well as the current and the voltage of one phase. For example, the copper losses $P_{\text {copper }}$ are simply expressed as

$$
P_{\text {copper }}=3 \cdot R_{p h} \cdot I_{p h}^{2} .
$$

The skin effect in the wires is neglected. Indeed, the maximal working frequency at $10,000 \mathrm{rpm}$ is $167 \mathrm{~Hz}$ and the

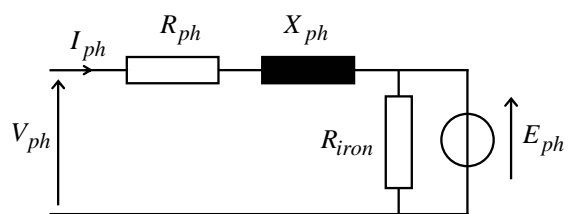

Figure 6. Single-phased equivalent circuit of the motor corresponding copper skin depth equals to $5 \mathrm{~mm}$, which is higher than the maximal possible radius of the wires.

The stator iron losses have been expressed by integration of $P_{\text {iron }}$, the specific iron losses in the stator laminations, which is classically expressed as a function of the maximal flux density $B_{m}$ and the angular frequency $\omega$ by

$$
P_{\text {iron }}=\left(k_{h} \cdot \omega \cdot B_{m}^{2}+k_{F} \cdot \omega^{2} \cdot B_{m}^{2}\right) \cdot m v_{\text {iron }},
$$

where $m v_{\text {iron }}$ is the specific mass of the stator, $k_{F}$ is computed knowing the thickness $e_{t}$ and the electrical conductivity $\sigma_{t}$ of the lamination by using

$$
k_{F}=\left(e_{t}^{2} \cdot \sigma_{t}\right) /\left(24 \cdot m v_{\text {iron }}\right) \text {, }
$$

and the coefficient $k_{h}$ is computed by using a value of $p_{\text {fer }}$ given by the vendor for a fixed flux density and a fixed frequency.

The rotor iron losses are included in the magnetic model which takes into account the eddy-currents in rotational parts.

Then the problem of optimization has the following mathematical form:

$$
\text { Maximize } \eta\left(p g_{i}\right) \text { with }\left\{\begin{array}{l}
B_{s y} \leq 1,2[\mathrm{~T}] \\
B_{t} \leq 1,2[\mathrm{~T}] \\
B_{r y} \leq 1,2[\mathrm{~T}] \\
h_{m_{\min }} \leq h_{m} \leq h_{m_{\max }} \\
V \leq V_{\max } \\
J_{c d} \leq 4\left[\mathrm{~A} / \mathrm{mm}^{2}\right] \\
1 \leq N_{s} \leq 25 \\
\tau_{r} \leq 33 \% \\
5 \leq \mathrm{h}_{\mathrm{t}} \leq 20[\mathrm{~mm}]
\end{array}\right. \text {, }
$$

where $\eta$ is the efficiency of the machine (including copper losses and both stator and rotor iron losses); $p g_{i}$ are the geometrical parameters; $B_{s y}, B_{t}$ and $B_{r y}$ are respectively the flux density in the stator yoke, the teeth and the rotor yoke; $h_{m}$ is the radial thickness of the PM; $V$ is the voltage of one phase; $J_{c d}$ is the current density in the slots; $N_{s}$ is the number of turn in serial per pole and per phase; $\tau_{r}$ the fill factor in one slot; and $h_{t}$ the height of one tooth. The optimization has been achieved by using the software Mathcad ${ }^{\circledR}$ and the non-linear method of Levenberg-Marquardt.

The results of the optimization are summarized in the TABLE II, which gives the geometrical parameters expressed as adimensional ratios because of confidentiality. The Figure 7 


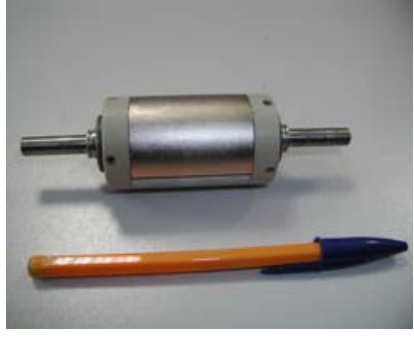

(a)

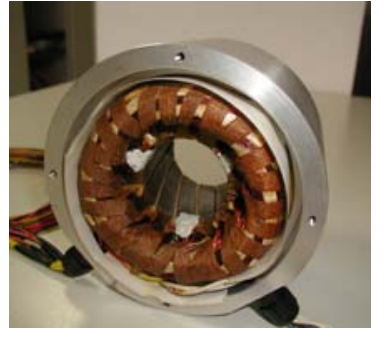

(b)
Figure 7. Photographs of the realized prototype. (a) Rotor, and (b) Stator

gives the photographs of the stator and the rotor of a prototype realized right to the results of the optimization.

In the next sections the authors present various theoretical characteristics of the machine, as well as the first experimental measurements.

\section{THEORETICAL CHARACTERISTICS OF THE MACHINE}

\section{A. Electrical Characteristics}

The electrical characteristics of the designed machine have been computed by using the AM described in the paragraph II.E. The obtained numerical values are summarized in the TABLE III.

\section{B. Electromechanical Characteristics}

The mechanical characteristic, giving the maximum possible torque that can be provided by the machine for a given rotational speed is plotted in Figure 8. The red curve gives the electromagnetic limit; it means that all the points bellow this curve can be obtained considering only the

TABLE III

ELECTRICAL CHARACTERISTICS OF THE MOTOR

\begin{tabular}{lr}
\hline \hline Characteristics & Values \\
\hline Battery voltage [V] & 120 \\
RMS voltage of one phase [V] & 50.9 \\
RMS current in one phase [A] & 3.34 \\
RMS current density in one phase [A/ $\left.\mathrm{mm}^{2}\right]$ & 3.94 \\
Back EMF coefficient [mWb] & 48 \\
Torque coefficient [mWb] & 143 \\
Resistance of one phase [m $\Omega]$ & 317 \\
Inductance of one phase [mH] & 0.507 \\
Mutual inductance of one phase [mH] & -0.227 \\
Synchronous inductance [mH] & 0.734 \\
\hline \hline
\end{tabular}

TABLE IV

POWER BALANCE IN THE MOtOR AT THE RATED POINT

\begin{tabular}{lr}
\hline \hline Characteristics & Values \\
\hline Copper losses [W] & 10.6 \\
Total iron losses [W] & 25.1 \\
Mechanical losses [W] & 8 \\
Mechanical power [W] & 500 \\
Efficiency [\%] & 92.0 \\
\hline \hline
\end{tabular}

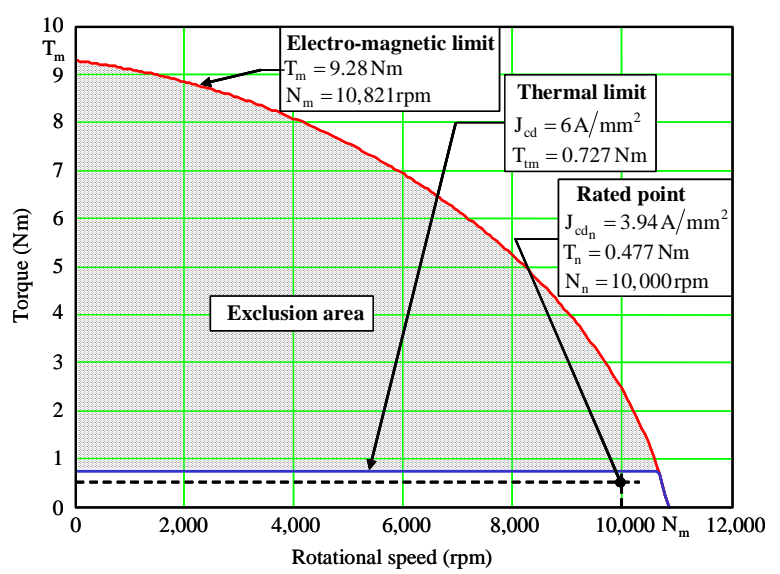

Figure 8. Theoretical mechanical characteristic

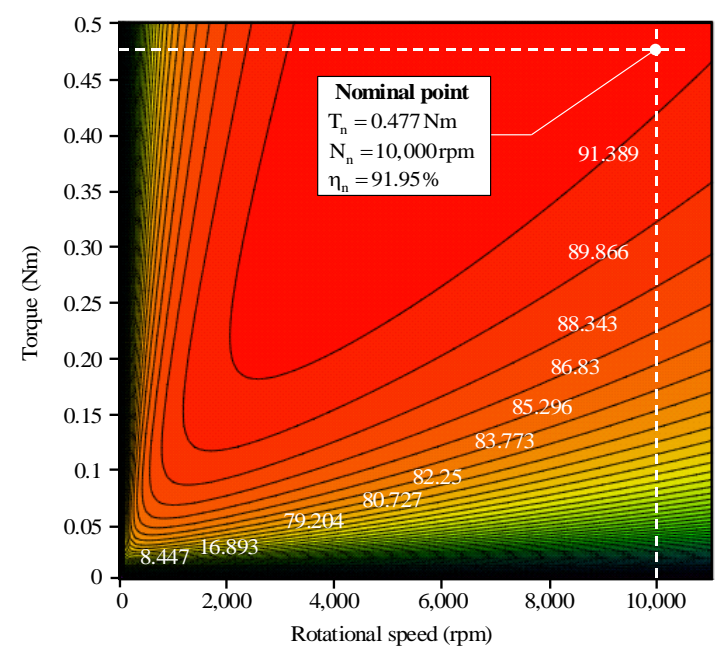

Figure 9. Isovalues of the efficiency in the $T-\Omega$ plane

electromagnetic point of view. But, due to the fact that the cooling is only achieved by natural convection, there is a thermal limit (horizontal blue curve); it means that, in steady state, the points between the red curve and the blue one are not possible because they lead to non-acceptable heating. Finally, the rated point defined in the specifications is plotted and it is possible to check that it belongs to the possible area of working, in the plane $\mathrm{T}-\Omega$.

The TABLE IV gives the different losses of the power balance at the rated point, i.e. $N_{n}=10,000 \mathrm{rpm}$ and $T_{n}=0.477 \mathrm{Nm}$. Then, to complete the characterization of the machine, the authors have plotted in Figure 9 the isovalues of the efficiency in the possible working area of the plane $T-\Omega$. This graph clearly shows a very large area where the efficiency is higher than $89 \%$, proving the quality of the energy conversion of the designed machine.

\section{EXPERIMENTAL CHARACTERISTICS OF THE MACHINE}

Today, the realized machine is under test at the L2ES. The complete experimental characterization is not yet available, but the authors present the first results in this section. 


\section{A. Description of the Test Bench}

In order to achieve the experimental characterization of the machine, a test bench has been developed. It consists of the studied PMSM which is coupled with a DC motor supplied by a DC electronic fed, for the first tests [see Figure 10]. In a second step, an ASM (more precisely a high-speed electric spindle) supplied by a four-quadrant electronic fed will be used.

\section{B. Fed and Control of the Motor}

The PMSM is fed by a voltage inverter. Thanks to a control of the current, by using hysteresis controllers, the inverter supplies the motor with three-phased quasi-sinusoidal currents. The $d S P A C E^{\circledR}$ system has been chosen for the regulation. This system has the advantage of being compatible with MatlabSimulink ${ }^{\circledR}$. The complete current control diagram is drawn in Simulink $^{\circledR}$ and it is directly transposed in language $C$ and compiled for $d S P A C E^{\circledR}$ by using the Toolbox Real Time Workshop $^{\circledR}$. Various measurements are available for the analysis or the regulation: for example the angular position or the voltages and the currents of each phase. The phase and the magnitude of the currents are imposed. For the present work, the authors have just controlled the magnitude of the currents

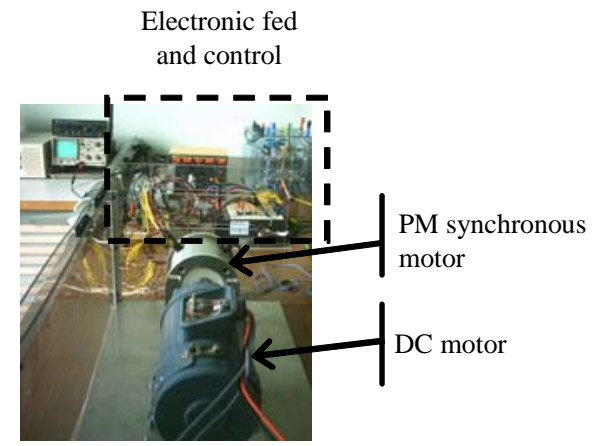

Figure 10. Photograph of the motor test bench

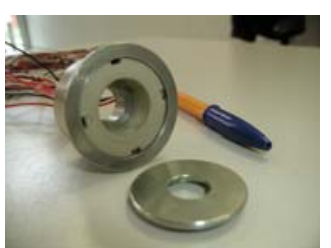

(a)

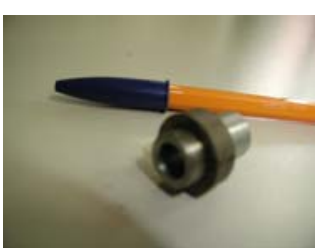

(b)

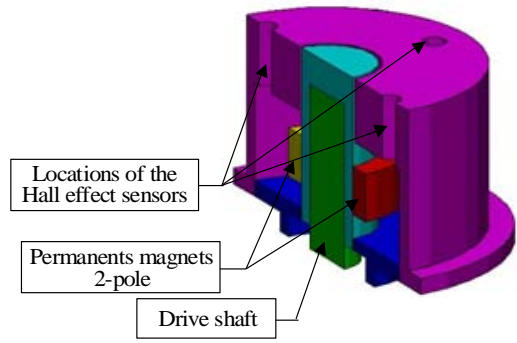

(c)

Figure 11. A PM position sensor. (a) Stator of PMPS, (b) "Image" of the turning parts motor, and (c) survey of PMPS and their difference of phase with the back EMF, thanks to the information of position given by a PM position sensor (PMPS) represented in Figure 11. The principle of this PMPS is simple; it has two PM (Sm-Co) which are placed in opposite on the axis of the motor. Two Hall-effect sensors are located on the stator of PMPS and deliver a voltage proportional to magnetic flux density. The two voltages delivered by the two sensors have the shapes of a cosine and sine (i.e. a cos-sin position sensor). The frequency of the two sine curves can enable us to know the rotational speed of the motor. The two signals enable us to create the three references of the threephased stator currents.

\section{First Experimental Results}

The back EMF of the machine has been measured at noload generator mode. The results are plotted in Figure 12 and compared with the results of 2D FEM simulations and the ones of the AM. It is possible to observe discrepancies between the theoretical and experimental results. Then, the results of the AM have been corrected by using a factor, $K_{3 D}$, modeling the three-dimensional (3D) end-effects [11], due to the fact that the PM length is higher than the stator length. This correction leads to an improvement of the agreement between theoretical and experimental results, proving the importance of the end-effects [see Figure 12]. Then, the TABLE $\mathrm{V}$ gives the electrical characteristics of the realized prototype showing again a good agreement with the theoretical results of the TABLE III.

\section{CONCLUSION}

In this paper, the authors have presented the optimal design of a high-speed PMSM for the drive of a FC air-compressor. The considered level of mechanical power is $500 \mathrm{~W}$ for the

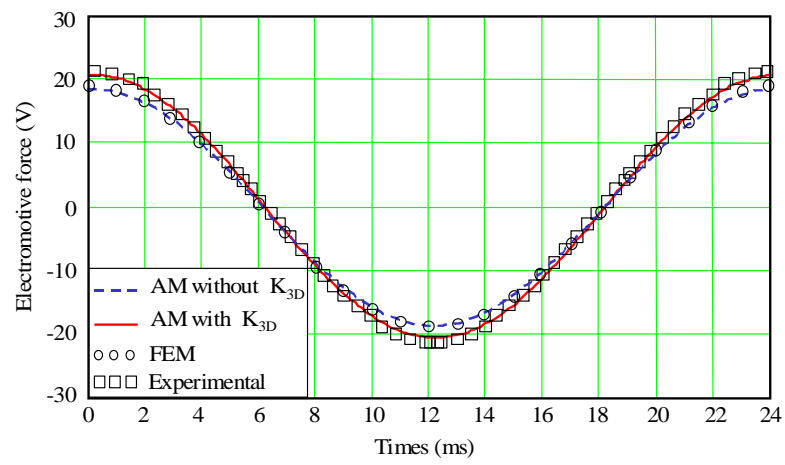

Figure 12. Theoretical and experimental chronograms of the back EMF

TABLE V

ELECTRICAL CHARACTERISTICS OF THE PROTOTYPE FIRST EXPERIMENTAL RESULTS

\begin{tabular}{lrr}
\hline \hline Characteristics & Values & Relative error \\
\hline Resistance of one phase $[\mathrm{m} \Omega]$ & 320 & $0.95 \%$ \\
Inductance of one phase $[\mathrm{mH}]$ & 0.502 & $0.98 \%$ \\
Mutual inductance of one phase $[\mathrm{mH}]$ & -0.291 & $28.2 \%$ \\
Synchronous inductance $[\mathrm{mH}]$ & 0.793 & $8 \%$ \\
\hline \hline
\end{tabular}


motor, which is the necessary power for a $5 \mathrm{~kW} \mathrm{FCS.} \mathrm{The} \mathrm{key}$ point of the design is the optimization of the energy consumption. The theoretical analysis has shown good efficiency of the optimized machine. The first experimental results seem to validate the computations; so that the authors think that the realized machine can be a good candidate for the drive of an air-compressor. Now, after the full tests, the next target is to couple the machine with a real compressor and to test it at the L2ES with a real FCS.

\section{AKNOWLEDGMENT}

The authors gratefully thank Dr Daniel Hissel (Senior Member, IEEE) for his kind contribution.

\section{REFERENCES}

[1] M. Purman and Z. Styczynski, "Power Flow investigations of a PEM fuel cell system", Transmission and Distribution Conference and Exposition, 2003 IEEE PES, Vol. 1, 7-12 September 2003, pp. 399-404.

[2] P. Rodatz, G. Paganelli, L. Guella, "Optimizing air supply control of a PEM fuel cell system”, Proceedings of the 2003 American Control Conference, Vol. 3, 4-6 June 2003, pp. 2043-2048.

[3] Pukrushpan, J.T.; Stefanopoulou, A.G.; Huei Peng, "Control of fuel cell breathing”, IEEE Control Systems Magazine, Vol. 24, Issue 2, April 2004, pp. 30-46.
[4] F. Dubas, C. Espanet, and A. Miraoui, "Analytical Modeling of NoLoad Flux Density in Surface Mounted Permanent Magnet Motors," in Proc. Int. ACEMP, Ïstanbul, Türkiye, pp. 283-290, 26-28 May 2004.

[5] F. Dubas, C. Espanet, and A. Miraoui, "Maximization of No-Load Flux Density in Surface Mounted Permanent Magnet Motors," in CdRom Int. ICEM, Cracovia, Poland, ISBN 12-345678-90 (pp. 01-06), 05-08 September 2004.

[6] F. Dubas, C. Espanet, and A. Miraoui, "Field diffusion equation in high-speed surface mounted permanent magnet motors, parasitic eddycurrent losses”, accepted with the ELECTROMOTION, Lausanne, Switzerland, pp. 01-06, 27-29 September 2005.

[7] FLUX2D, User Manual, Version 9.1, Cedrat S.A Electrical Engineering, 10 Chemin de pré carré, Zirst, 38246 Meylan Cedex, France.

[8] Q. Gu and H. Gao, "Effect of slotting in PM electrical machines", Elect. Mach. Power Syst., Vol. 10, No. 2, pp. 273-284, 1985.

[9] F. Dubas, H.S. Zire, S. Srairi, C. Espanet, and A. Miraoui, "Étude de la Désaimantation dans l'Air d'un Inducteur Cylindrique de Machines à Aimants Permanents montés en Surface," in CdRom Électrotechnique du Futur (EF), Grenoble, France, pp. 01-06, 14-15 September 2005.

[10] K.J. Binns, P.J.G. Lisboa, and M.S.N. Al-din, "The use of canned rotors in high speed permanent magnet machines", in Proc. Int. Conf. on Electr. Mach. and Drives, No. 341, pp. 21-25, 1991.

[11] F. Jean, P. Brochet, and C. Rombaut, "Taking into account some threedimensional effects in the modelling of a brushless permanent-magnet motor", in Proc. ELECTRIMACS, Saint-Nazaire, France, Vol. 2, pp. 639-644, 1996. 